\title{
Human bone marrow megakaryocytes and platelets express PPAR $\gamma$, and PPAR $\gamma$ agonists blunt platelet release of CD40 ligand and thromboxanes
}

Filiz Akbiyik, Denise M. Ray, Kelly F. Gettings, Neil Blumberg, Charles W. Francis, and Richard P. Phipps

Peroxisome proliferator-activated receptor $\gamma$ (PPAR $\gamma)$ is a ligand-activated transcription factor important in lipid metabolism, diabetes, and inflammation. We evaluated whether human platelets and megakaryocytes express PPAR $\gamma$ and whether PPAR $\gamma$ agonists influence platelet release of bioactive mediators. Although PPAR $\gamma$ is mainly considered a nuclear receptor, we show that enucleate platelets highly express PPAR $\gamma$ protein as shown by Western blotting, flow cytometry, and immunocytochemistry. Meg-01 megakaryocyte cells and human bone marrow megakaryocytes also express PPAR $\gamma$. Platelet and Meg-01 PPAR $\gamma$ bound the PPAR $\gamma$ DNA consensus sequence, and this was enhanced by PPAR $\gamma$ agonists. Platelets are essential not only for clotting, but have an emerging role in inflammation in part due to their release or production of the proinflammatory and proatherogenic mediators CD40 ligand (CD40L) and thromboxanes (TXs). Platelet incubation with a natural PPAR $\gamma$ agonist, $15 d-P G J_{2}$, or with a potent synthetic PPAR $\gamma$ ligand, rosiglitazone, prevented thrombin-induced CD40L surface expres- sion and release of CD40L and thromboxane $B_{2}\left(T X B_{2}\right)$. 15d-PGJ $J_{2}$ also inhibited platelet aggregation and adenosine triphosphate (ATP) release. Our results show that human platelets express PPAR $\gamma$ and that PPAR $\gamma$ agonists such as the thiazolidinedione class of antidiabetic drugs have a new target cell, the platelet. This may represent a novel mechanism for treatment of inflammation, thrombosis, and vascular disease in high-risk patients. (Blood. 2004;104:1361-1368)

๑) 2004 by The American Society of Hematology

\section{Introduction}

Peroxisome proliferator-activated receptors (PPARs) are members of a nuclear hormone receptor superfamily of ligandactivated transcription factors. There are 3 PPAR subtypes: $\operatorname{PPAR} \alpha, \operatorname{PPAR} \beta / \delta$, and PPAR $\gamma$. The genes encoding the PPAR subtypes each reside on different chromosomes and have distinct tissue expression patterns. ${ }^{1}$ While many reports focus on PPAR expression in the nucleus, PPAR $\gamma$, in particular, is also found in the cytoplasm. . $^{2,3}$

PPAR $\gamma$ is highly expressed in white adipose tissue and was initially described as important for regulating gene expression in metabolism, insulin responsiveness, and adipocyte differentiation. ${ }^{4,5}$ While PPAR $\gamma$ was originally thought to be found mainly in fat tissue, it is in fact widely expressed by many types of cells including macrophages, B and T lymphocytes, epithelial, endothelial, smooth muscle, and fibroblastic cells. ${ }^{2,6-11}$ PPAR $\gamma$ has also come to prominence as PPAR $\gamma$ agonists play an important role in immune function by dampening inflammation, attenuating macrophage/monocyte synthesis of proinflammatory cytokines, and inducing apoptosis in B lymphocytes. ${ }^{2,6,12,13}$ PPAR $\gamma$ has also emerged as a key target for malignant cells as PPAR $\gamma$ agonists have shown therapeutic potential for B lymphoma and various epithelialderived cancers. ${ }^{2,14,15}$

From the Department of Biochemistry, Faculty of Medicine, Hacettepe University, Ankara, Turkey; the Departments of Environmental Medicine, Pathology and Laboratory Medicine, and Microbiology and Immunology, and the Lung Biology and Disease Program, University of Rochester School of Medicine and Dentistry; and the Hematology/Oncology Unit, Department of Medicine, University of Rochester School of Medicine and Dentistry, Rochester, NY.

Submitted March 10, 2004; accepted April 26, 2004. Prepublished online as Blood First Edition Paper, May 6, 2004; DOI 10.1182/blood-2004-03-0926.

Supported by TUBITAK (The Scientific and Technical Research Council of Turkey)/NATO-A2, National Institutes of Health (NIH) Training Program in Oral Infectious Diseases (T32-DE07165, NIH DE011390, and ES001247), a Cancer
Megakaryocytes are the biggest cell of the bone marrow and the parent cell of platelets. Platelets are derived from the cytoplasm of megakaryocytes and are released to the bloodstream under the effects of cytokines such as interleukin-6 (IL-6) and IL-11.16,17 Platelets are enuclear cells that have a plasma membrane, surface-connected canalicular and tubular system, mitochondria, granules, lysosomes, and peroxisomes. ${ }^{18}$ Recent studies demonstrate that platelets and many of their products are important not only in hemostasis, but have now emerged as important in immunoregulation and inflammation. For example, platelets produce key inflammatory mediators such as transforming growth factor- $\beta$ (TGF- $\beta$ ), thromboxane $\mathrm{A}_{2}\left(\mathrm{TXA}_{2}\right)$, and prostaglandin $\mathrm{E}_{2}$ $\left(\mathrm{PGE}_{2}\right) .{ }^{19-21}$ The recent key demonstration that activated human platelets express and expel CD40 ligand (CD40L, formally known as CD154) provides a mechanism of interaction with CD40 expressing cells that include macrophages and vascular structural cells. $22-25$ These cells when activated through CD40 express cyclooxygenase-2 (Cox-2) and prostaglandins, adhesion molecules, and cytokines such as IL-6 and tissue factor. ${ }^{26,27}$ Many new studies now demonstrate that elevated CD40L levels in blood are associated with acute coronary syndromes and stroke. ${ }^{28}$ Interestingly, elevated serum levels of CD40L predict an increased cardiovascular risk in a healthy population. ${ }^{29}$

Center Discovery Award (HL-30616), and RR14682 from the National Center for Research Resources of the NIH.

F.A. and D.M.R. contributed equally to this work.

Reprints: Richard P. Phipps, Box 850, Department of Environmental Medicine, University of Rochester School of Medicine and Dentistry, 601 Elmwood Ave, Rochester, NY, 14642; e-mail: richard_phipps@urmc.rochester.edu.

The publication costs of this article were defrayed in part by page charge payment. Therefore, and solely to indicate this fact, this article is hereby marked "advertisement" in accordance with 18 U.S.C. section 1734.

(C) 2004 by The American Society of Hematology 
The enucleate platelet is not usually thought of as a cell containing transcription factors. Nonetheless, we investigated whether the human megakaryoblast cell line (Meg-01), human bone marrow megakaryocytes, and human platelets express PPAR $\gamma$ protein and whether platelets themselves might be targets of selected PPAR $\gamma$ agonists. Herein, we report the surprising findings that human megakaryocytes and platelets do express PPAR $\gamma$ and are susceptible to PPAR $\gamma$ agonists that dampen platelet release of the key proinflammatory and proatherogenic mediators $\mathrm{CD} 40 \mathrm{~L}$ and thromboxane $\mathrm{B}_{2}\left(\mathrm{TXB}_{2}\right)$. These novel findings support a role for the PPAR $\gamma$ system in modulating platelet function.

\section{Materials and methods}

\section{Cell line and culture conditions}

Meg-01 cells were purchased from the American Type Culture Collection (Rockville, MD) and are widely used as a model of human megakaryocytes. ${ }^{30}$ Meg-01 cells were cultured in RPMI-1640 tissue culture medium (Invitrogen, Carlsbad, CA) supplemented with 10\% fetal bovine serum (FBS; Invitrogen), $10 \mathrm{mM}$ HEPES ( $N$-2-hydroxyethylpiperazine- $N^{\prime}-2$ ethanesulfonic acid; Sigma, St Louis, MO), 2 mM L-glutamine (Invitrogen), $4.5 \mathrm{~g} / \mathrm{L}$ glucose (Invitrogen), and $50 \mu \mathrm{g} / \mathrm{mL}$ gentamicin (Invitrogen).

\section{Preparation of platelets}

Blood samples $(500 \mathrm{~mL})$ were collected from healthy volunteers by venipuncture into a CPDA-1 blood collection bag (Baxter Healthcare, Deerfield, IL). The platelet-rich plasma (PRP) was obtained by centrifugation at $1800 \mathrm{~g}$ for 8 minutes and extracted into the transfer bag (Charter Medical, Winston-Salem, NC) at room temperature. The Pall Biomedical Purecell LRF high-efficiency leukoreduction filter (East Hills, NY) was used to reduce leukocytes, microaggregates, and anaphylatoxin C3a. Leukocytes were removed by adherence in the filter. Platelets were washed with 0.9\% saline using a COBE 2991 Blood Cell Processor (Lakewood, CO). Cell counts were performed on an Abbott Cell-Dyn 1700 (Abbott Park, IL), and the final platelet count was $5.5 \times 10^{10} /$ unit. The maximum numbers of contaminant nonplatelet cells were $1 \times 10^{5}$ white blood cells and $1 \times 10^{8}$ red blood cells, the percentages being $0.0001 \%$ and $0.1818 \%$ of platelets, respectively. Pooled PRP was prepared by the same procedure from 2 to 5 donors and combined into a pool bag (Charter Medical). The platelets were isolated by an additional centrifugation step at $1200 \mathrm{~g}$ of the PRP for 4 minutes, and the pellet was washed twice with $1 \times$ phosphatebuffered saline (PBS).

\section{Western blot for PPAR $\gamma$}

Meg-01 and platelet total protein was isolated using nonidet P-40 lysis buffer containing a protease inhibitor cocktail (4-(2-aminoethyl)-benzenesulfonyl fluoride, pepstatin A, transepoxysuccinyl-L-leucylamido (4guanidino) butane, bestatin, leupeptin, and aprotinin; Sigma). Total protein was quantified with a bicinchoninic acid (BCA) protein assay kit (Pierce, Rockford, IL). A total of $15 \mu \mathrm{g}$ protein was electrophoresed on $10 \%$ denaturing polyacrylamide-stacking gels and transferred to nitrocellulose membrane (Amersham, Piscataway, NJ) at $4^{\circ} \mathrm{C}$. After blocking with $10 \%$ Blotto (PBS/0.1\% Tween 20 and $10 \%$ milk) for 2 hours at room temperature, membranes were then incubated with a mouse monoclonal anti-PPAR $\gamma$ antibody from Santa Cruz Biotechnology (1:1000; Santa Cruz, CA) or with a rabbit polyclonal anti-PPAR $y$ antibody from Calbiochem (1:5000; San Diego, CA) diluted in 2.5\% Blotto for 1 hour. They were then washed in PBS $/ 0.1 \%$ Tween 20 and incubated with a goat anti-rabbit horseradish peroxidase (Santa Cruz Biotechnology) secondary antibody at 1:2000 dilution for 1 hour. The membranes were washed in PBS/0.1\% Tween 20 and bands were visualized using a Western Lightning chemiluminescence kit according to the manufacturer's instructions (Perkin Elmer Life Sciences, Boston, MA). The platelet PPAR $\gamma$ band detected by Western blot was identified as PPAR $\gamma$ by MALDI-TOF mass spectroscopy (MS) peptide mapping analysis at the University of Rochester MicroChemical Protein/Peptide Core Facility (data not shown).

\section{Meg-01 and human platelet immunocytochemistry for PPAR $\gamma$}

Meg-01 cells $\left(1 \times 10^{5}\right)$ and platelets $\left(1 \times 10^{7}\right)$ were cytospun on slides and fixed with $1 \%$ paraformaldehyde and stained with a rabbit polyclonal anti-PPAR $\gamma$ antibody (Santa Cruz Biotechnology) or with an immunoglobulin $\mathrm{G}(\mathrm{IgG})$ isotype control (both at $4 \mu \mathrm{g} / \mathrm{mL}$ ) (Santa Cruz Biotechnology) as described. ${ }^{7}$ Slides were developed with aminoethyl carbazole (AEC) reagent (Zymed Laboratories, San Francisco, CA) and visualized with an Olympus BX51 microscope (Melville, NY). Photographs were taken using a SPOT camera with SPOT RT software (New Hyde Park, NY). The objectives used were a $60 \times$ Olympus UPlan F1 with a 1.25 numerical aperture and a $100 \times$ Olympus UPlan F1 with a 1.3 numerical aperture.

\section{Preparation of human bone marrow smears and immunocytochemistry for PPAR $\gamma$}

Human bone marrow aspiration material was obtained from the hip bone of anemia patients. A drop of material about $2 \mathrm{~mm}$ in diameter was put onto slides and immediately spread over by coverslip and air dried for 24 hours. Smears were fixed with acetone-methanol solutions. Except for the fixation step, immunocytochemistry was performed as described. ${ }^{7}$ Slides were stained with a mouse monoclonal anti-PPAR $\gamma$ antibody (Santa Cruz Biotechnology) or with IgG1 isotype control (both at $4 \mu \mathrm{g} / \mathrm{mL}$ ) (Santa Cruz Biotechnology), and biotin-labeled horse anti-mouse IgG (Vector Laboratories, Burlingame, CA) was used as secondary antibody. After staining for PPAR $\gamma$, counterstaining with hematoxylin was performed. One slide from the same patient was stained with a Diff-Quik stain set (Dade Behring, Newark, DE)

\section{cDNA synthesis and RT-PCR assay}

Total RNA was extracted with Tri-Reagent from platelets and Meg-01 according to the supplier's protocol (MRC, Cincinnati, OH). A total of 2 $\mu \mathrm{g}$ RNA was used for the reverse-transcription (RT) reaction, and polymerase chain reaction (PCR) for PPAR $\gamma$ and $\beta$-actin was performed as described. ${ }^{7}$ A reaction was performed without reverse transcriptase for each cDNA synthesis and used as a negative control in the PCR cDNA $(10 \mu \mathrm{L})$ was used in the PCR reaction. The RT-PCR products were separated by gel electrophoresis on $1 \%$ agarose gels and stained with ethidium bromide. Adipose tissue and THP1 human monocyte cells were used as positive controls.

\section{Flow cytometric analysis}

The washed platelets were resuspended and incubated in $1 \mathrm{~mL}$ fluorescenceactivated cell-sorter (FACS) lysis solution (FLS; BD Biosciences, Immunocytometry Systems, San Jose, CA) at a concentration of $1 \times 10^{7} / \mathrm{mL}$ in $1 \times$ FLS for 10 minutes in the dark at room temperature. After centrifugation at $500 \mathrm{~g}$ for 5 minutes, the cells were permeabilized with $1 \times$ FLS $+0.2 \%$ saponin (Sigma) for 10 minutes. Samples then were incubated with 8 $\mu \mathrm{g} / \mathrm{mL}$ monoclonal fluorescein isothiocyanate (FITC)-labeled anti-PPAR $\gamma$ antibody (BD Biosciences, San Diego, CA) or FITC-labeled IgG1 isotype control (BD Biosciences) for 30 minutes in the dark at room temperature. Cells were washed with $1 \times$ PBS containing $1 \%$ bovine serum albumin (BSA) and $0.1 \%$ sodium azide $\left(\mathrm{NaN}_{3}\right)$. Samples were resuspended in $1 \%$ paraformaldehyde and analyzed on a Becton Dickinson FACSCalibur flow cytometer (San Jose, CA).

For CD40L surface staining, washed platelets were pretreated with PPAR $\gamma$ agonists for 15 minutes and then exposed to $0.8 \mathrm{U} / \mathrm{mL}$ thrombin for 60 minutes at $37^{\circ} \mathrm{C}$ in the presence of $200 \mu \mathrm{M}$ fibrinogen receptor antagonist (Bachem, King of Prussia, PA) and 5 mM EDTA (ethylenediaminetetraacetic acid; Sigma) to prevent clotting. The platelets were then stained for CD40L using a mouse IgG1 anti-human CD40L biotinylated monoclonal antibody (Ancell, Bayport, MN), or a mouse IgG1 isotype control antibody (Caltag, Burlingame, CA) followed by streptavidin conjugated to allophycocyanin (Caltag). 


\section{PPAR $\gamma$ activity assay}

Concentrated platelets were washed twice and treated with $20 \mu \mathrm{M}$ $15 \mathrm{~d}_{-} \mathrm{PGJ}_{2}$ (Biomol, Plymouth Meeting, PA), rosiglitazone (Cayman Chemical, Ann Arbor, MI), ciglitazone (Biomol), or dimethyl sulfoxide (DMSO, vehicle control) for 2 hours at $37^{\circ} \mathrm{C}$. Platelets were lysed with hypotonic buffer (10 mM HEPES-KOH [pH 7.9], $1.5 \mathrm{mM} \mathrm{MgCl} 2,10 \mathrm{mM} \mathrm{KCl}, 0.5$ $\mathrm{mM}$ dithiothreitol [DTT], $0.5 \%$ nonidet P-40, and $0.2 \mathrm{mM}$ phenylmethylsulfonyl fluoride [PMSF]), $10 \mu \mathrm{g}$ of cell extract was incubated in each well of TransAM PPAR $\gamma$ assay kit (Active Motif, Carlsbad, CA), and PPAR $\gamma$ DNA binding was determined as per the manufacturer's protocol.

\section{Electrophoretic mobility shift assay (EMSA) for PPAR $\gamma$}

Nuclear extracts of Meg-01 cells were prepared as described previously. ${ }^{31}$ Cells were treated with $5 \mu \mathrm{M} 15 \mathrm{~d}-\mathrm{PGJ}_{2}, 10 \mu \mathrm{M}$ ciglitazone, or DMSO (vehicle control) for 4 hours. The cells were washed in cold PBS and then incubated on ice in hypotonic buffer (10 mM HEPES-KOH [pH 7.9], 1.5 $\mathrm{mM} \mathrm{MgCl} 2,10 \mathrm{mM} \mathrm{KCl}, 0.5 \mathrm{mM}$ DTT, $0.5 \%$ nonidet P-40, and $0.2 \mathrm{mM}$ PMSF) for 10 minutes. The lysates were vortexed for 10 seconds and centrifuged for 15 seconds. The pellet was isolated carefully and resuspended in $80 \mu \mathrm{L}$ hypertonic buffer (20 mM HEPES-KOH [pH 7.9], $1.5 \mathrm{mM}$ $\mathrm{MgCl}_{2}, 25 \%$ glycerol, $420 \mathrm{mM} \mathrm{NaCl}, 0.2 \mathrm{mM}$ EDTA, $0.5 \mathrm{mM}$ DTT, and 0.2 $\mathrm{mM}$ PMSF). After incubation on ice for 20 minutes, lysates were centrifuged for 20 seconds and the supernatant containing the nuclear protein was transferred to new tubes. Protein quantification was performed using a BCA assay kit. Platelet protein isolation was done as described for the PPAR $\gamma$ activity assay. For the gel shift assay of Meg-01 and platelets, the consensus sequence for PPAR $\gamma\left(5^{\prime}\right.$-CAAAACTAGGTCAAAGGTCA$\left.3^{\prime}\right)$ was labeled with $[\gamma-32 \mathrm{P}]$ adenosine triphosphate (ATP) using T4 Polynucleotide Kinase (Life Technologies, Bethesda, MD). Micro Bio-Spin P-30 Tris Chromatography Columns were used to remove the unbound nucleotides (Bio-Rad, Hercules, CA). Meg-01 or platelet protein extracts were incubated with binding buffer ( $10 \mathrm{mM}$ Tris [tris(hydroxymethyl)aminomethane]- $\mathrm{HCl}$ [pH 7.5], $50 \mathrm{mM} \mathrm{NaCl}, 4 \%$ glycerol, $1 \mathrm{mM} \mathrm{MgCl}, 0.5$ mM EDTA, $0.5 \mathrm{mM}$ DTT, and $0.05 \mathrm{mg} / \mathrm{mL}$ poly (dI-dC)) and 50000 counts of labeled oligonucleotide or cold oligonucleotide for 15 minutes at room temperature. Supershift experiments were completed by adding $2 \mu \mathrm{g}$ of the anti-PPAR $\gamma$ antibody (Calbiochem) to the binding reaction. The samples were then run on a $4 \%$ nondenaturing polyacrylamide gel. The gel was dried on a Savant SGD 2000 gel dryer (Savant, Farmingdale, NY) for 1 hour at $50^{\circ} \mathrm{C}$ and exposed to film overnight.

\section{Measurement of CD40L and $\mathrm{TXB}_{2}$}

Platelets were isolated as described in "Preparation of platelets" and cultured with buffer or with $15 \mathrm{~d}_{-} \mathrm{PGJ}_{2}$ or rosiglitazone (both at $20 \mu \mathrm{M}$ ) for 15 minutes at $37^{\circ} \mathrm{C}$. Platelets were then activated with $0.8 \mathrm{U} / \mathrm{mL}$ thrombin or buffer, and samples were taken at the 5-, 10-, 15-, 30-, and 60-minute time points to measure human soluble CD40L and $\mathrm{PGE}_{2}$. CD40L assays were performed with a commercially available enzyme-linked immunosorbent assay (ELISA) specific for CD40L (Bender Biomedical Systems, San Bruno, CA). Virtually identical results were obtained using an ELISA for CD40L developed in our lab (data not shown). The stable end product of platelet $\mathrm{TXA}_{2}$ synthesis, namely $\mathrm{TXB}_{2}$, was measured using a highly specific enzyme immunoassay from Cayman Chemical as per the manufacturer's directions.

\section{Platelet aggregation and ATP release}

Platelet aggregation was performed using the turbidimetric method of Born $^{32}$ with simultaneous measurement of ATP release using a Chrono-log Lumi-aggregometer with AGGRO/LINK for Windows Software version 5.1.6 (Chrono-log, Havertown, PA). Blood was collected by clean venipuncture from healthy donors who abstained from drugs known to affect platelet aggregation into $0.105 \mathrm{M} /$ sodium citrate. PRP was prepared by centrifugation at $150 \mathrm{~g}$ for 10 minutes at $20^{\circ} \mathrm{C}$, and the platelet count adjusted to $250 \times 10^{9} / \mathrm{L}$ by mixing PRP and platelet-poor plasma from the same donor. All experiments were performed within 3 hours of blood collection. Aggregation was performed with adenosine diphosphate (ADP), and the slope of aggregation and amplitude was computed using accompanying software. The effects of the PPAR $\gamma$ agonist $15 \mathrm{~d}-\mathrm{PGJ}_{2}$ were tested by addition of varying concentrations to PRP for 15 minutes before aggregation. The $15 \mathrm{~d}-\mathrm{PGJ}_{2}$ was dissolved in DMSO, with a final concentration of DMSO in the samples of approximately $0.1 \%$. Control experiments showed no effect of this concentration of DMSO on platelet aggregation or release.

\section{Statistics}

Statistical analysis of time-dependent changes in supernatant levels of soluble CD40L ( $\mathrm{SCD} 40 \mathrm{~L}$ ) and $\mathrm{TXB}_{2}$ used the log-rank test performed using Statview (SAS Institute, Cary, NC). $P$ values of less than .05 were considered significant.

\section{Results}

\section{Meg-01 megakaryocytes and human blood platelets express PPAR $\gamma$ protein}

Meg-01 cells have been extensively used as a model of human megakaryocytes. ${ }^{30}$ To determine whether megakaryocytes and platelets express PPAR $\gamma$ protein we first tested Meg-01 cells and human platelets by Western blot for PPAR $\gamma$. Meg-01 cells and platelets were lysed and the protein was analyzed for PPAR $\gamma$ by Western blot using commercially available and widely used anti-PPAR $\gamma$ antibodies. Meg-01 cells express PPAR $\gamma$ protein that co-migrated with human fat tissue PPAR $\gamma$, used as a known positive control (Figure 1A). We next evaluated highly purified human platelets for PPAR $\gamma$ expression. There were 3 different single donor platelets and 3 multiple donor pooled platelet samples tested for PPAR $\gamma$ using 2 different anti-PPAR $\gamma$ antibodies (Figure 1B-C). Human platelets express a PPAR $\gamma$ band, which migrated similarly to the adipose tissue PPAR $\gamma$ band. While the platelet preparations were highly purified ( $>99.99 \%$ platelets), they did contain the rare white blood cell. To determine how many white blood cells were needed to generate a PPAR $\gamma$ band on a Western blot, experiments were completed with different numbers of white blood cells. At least $1 \times 10^{6}$ white blood cells were needed to show a PPAR $\gamma$ band on Western blots (data not shown). Therefore contamination with white blood cells in purified platelets could not account for the Western blot signal. Western blot experiments of red blood cells were also were completed for PPAR $\gamma$ and red blood
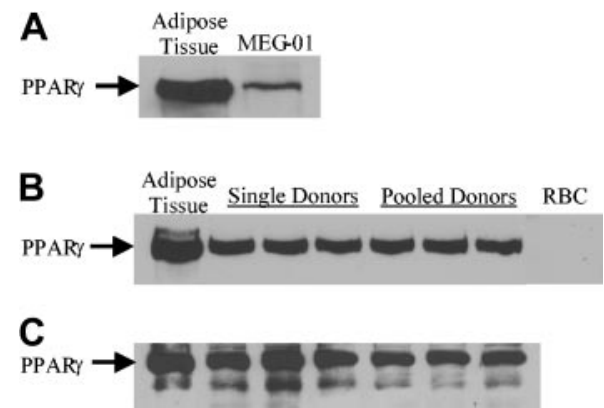

Figure 1. PPAR $\gamma$ protein is expressed in the human megakaryoblast cell line, Meg-01, and by human platelets. (A) Western blot of Meg-01 cell line (15 $\mu \mathrm{g})$ using a polyclonal anti-PPAR $\gamma$ antibody (Calbiochem). PPAR $\gamma$ bands co-migrated with the human adipose tissue protein extract $(15 \mu \mathrm{g})$ used as positive control. (B-C) Platele cell lysates $(15 \mu \mathrm{g})$ from rigorously purified single donor or pooled platelets were analyzed by Western blot for PPAR $\gamma$ using 2 different anti-PPAR $\gamma$ antibodies (panel B is monoclonal anti-PPAR $\gamma$ [Santa Cruz Biotechnology]; panel $\mathrm{C}$ is polyclonal anti-PPAR $\gamma$ [Calbiochem]). Human adipose tissue protein extract $(5 \mu \mathrm{g})$ was used as positive control (left lane). The PPAR $\gamma$ protein was shown for 3 different single donor and pooled platelet samples. Purified human red blood cells $(30 \mu \mathrm{g})$ are negative for PPAR $\gamma(B)$. Data are representative of more than 5 experiments. 
cells do not express PPAR $\gamma$ (Figure 1B). Additionally, PPAR $\gamma$ of platelet origin was confirmed by MALDI-TOF mass spectroscopy peptide mapping (data not shown).

The presence of PPAR $\gamma$ in Meg-01 cells and human platelets was further examined by immunocytochemistry. Meg-01 cells (Figure 2A) and platelets (Figure 2B) contain PPAR $\gamma$ protein, confirming the Western blot data. The PPAR $\gamma$ staining pattern of Meg-01 is cytoplasmic, as well as nuclear. In platelets, the staining pattern for PPAR $\gamma$ appeared throughout the cell, with apparent denser staining in platelet granules.

To further demonstrate expression of PPAR $\gamma$ protein in human platelets, flow cytometry experiments were performed. Concentrated and washed human platelets were incubated with monoclonal FITC-labeled anti-PPAR $\gamma$ antibody or FITC-labeled IgG1 isotype for 30 minutes and analyzed on a Becton Dickinson FACS Caliber flow cytometer. Platelets, being very small enucleate cells, have a low forward- and side-scatter profile compared with white blood cells. The flow cytometry results showed that PPAR $\gamma$ protein was expressed in more than $85 \%$ of platelets (Figure 2C).

\section{Human bone marrow megakaryocytes express PPAR $\gamma$ protein}

Based on the fact that platelets and the Meg-01 cells expressed PPAR $\gamma$ protein, we hypothesized that human megakaryocytes
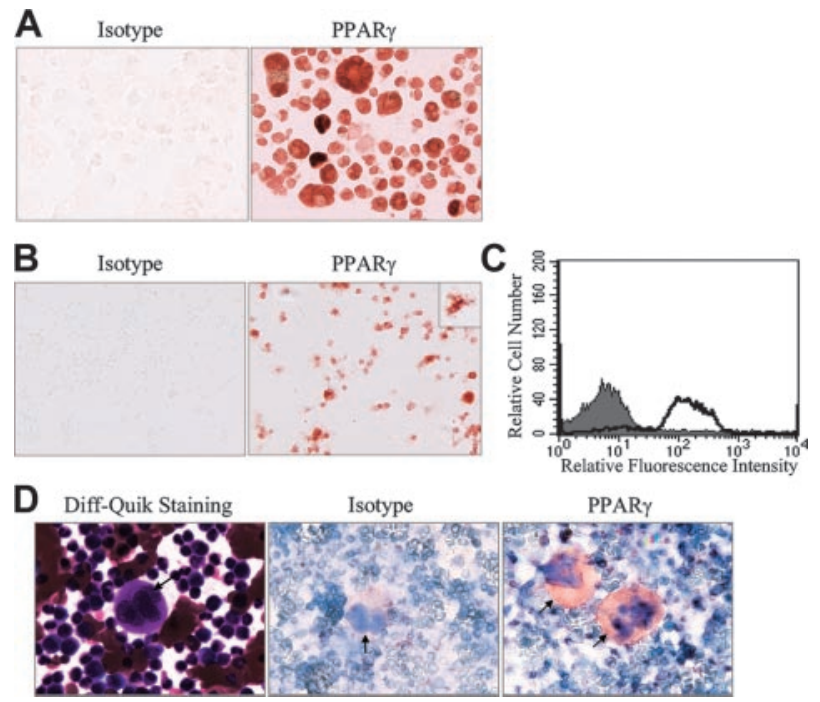

Figure 2. Immunocytochemistry demonstrating PPAR $\gamma$ expression in human megakaryoblast cells and platelets. Immunocytochemistry was performed with a rabbit polyclonal anti-PPAR $\gamma$ antibody as described in "Materials and methods." Nonspecific staining was assessed using a rabbit IgG isotype control. (A) Nucleated cells and enucleated plateletlike cells of the Meg-01 cell line were stained for PPAR $\gamma$. Meg-01 cells stain in the nucleus and the cytoplasm. Results were repeated 4 times with separate preparations of Meg-01 cells. Original magnification is $\times 600$. (B) Human platelets express PPAR $\gamma$. The staining pattern for PPAR $\gamma$ is throughout the platelets. Data are representative of 4 different donor platelet experiments with similar results. Original magnification is $\times 1000$. The inset represents 1 platelet with final magnification of $\times 2000$. (C) Flow cytometric analysis for intracellular expression of PPAR $\gamma$ in human platelets. Purified platelets were washed and stained with monoclonal FITC-labeled anti-PPAR $\gamma$ antibody (open histogram) or FITC-labeled lgG1 isotype control (shaded histogram) as described in "Materials and methods." Forward- and side-scatter gates were set to analyze only platelets. This experiment was repeated 3 times with similar results. (D) Immunocytochemistry of human bone marrow megakaryocyte for PPAR $\gamma$. (Left) Diff-Quik staining of a human bone marrow megakaryocyte. Immunohistochemistry was performed with a mouse monoclonal PPAR $\gamma$ antibody as described in "Materials and methods." (Right) PPAR $\gamma$ expression. (Middle) Mouse IgG1 isotype control was also used to show nonspecific staining. In addition to PPAR $\gamma$ immunostaining, light counterstaining was performed with hematoxylin to visualize the cells. The arrows are pointing at human megakaryocytes. Original magnification is $\times 600$. Data are representative of 4 experiments from 4 patients with similar results. would also express PPAR $\gamma$ protein. Expression of PPAR $\gamma$ in human bone marrow megakaryocytes was detected by immunocytochemistry using a monoclonal anti-PPAR $\gamma$ antibody. Human bone marrow was stained with Diff-Quik to identify human megakaryocytes (Figure 2D). The megakaryocyte is the largest cell of bone marrow with multilobated nuclei and abundant granular cytoplasm. Bone marrow smears were also prepared for immunocytochemistry to stain for PPAR $\gamma$. The right-hand panel of Figure 2D shows staining of human megakaryocytes for PPAR $\gamma$. The middle panel shows no staining with an isotype control antibody (smear is lightly counterstained with hematoxylin).

\section{PPAR $\gamma$ mRNA is expressed in the Meg-01 cell line but not in platelets}

Expression of PPAR $\gamma$ mRNA in Meg-01 and platelets was examined by RT-PCR. Platelets, while enucleate, do express a range of mRNA species. ${ }^{33}$ Total RNA was isolated from Meg-01 cells and single donor or pooled platelets and reverse transcribed as described in "Materials and methods." Then cDNA was run in PCR reactions with control $\beta$-actin primers or primers specific for human PPAR $\gamma$. RNA from human adipose tissue and THP1 human monocyte cells was used as positive control for PPAR $\gamma$. The results revealed a single RT-PCR product of the expected size of $360 \mathrm{bp}$ for PPAR $\gamma$ in adipose tissue (Figure 3, lane 2). Meg-01 cells and the THP1 monocytic cells express PPAR $\gamma$ mRNA (lanes 6 and 7 , respectively). PPAR $\gamma$ mRNA was not present in platelet samples (lanes 3-5). All samples did express $\beta$-actin mRNA, consistent with reports that platelets express mRNA encoding $\beta$-actin. ${ }^{34}$

\section{Meg-01 PPAR $\gamma$ has DNA binding ability that is enhanced by treatment with PPAR $\gamma$ ligands}

To determine if the PPAR $\gamma$ protein in Meg- 01 cells can bind DNA, gel shift assays were performed. In many systems enhanced DNA binding is observed if PPAR $\gamma$-expressing cells are first exposed to a PPAR $y$ agonist. ${ }^{35}$ Meg-01 cells were treated with the PPAR $y$ agonists $15 \mathrm{~d}-\mathrm{PGJ}_{2}(5 \mu \mathrm{M})$ or ciglitazone $(10 \mu \mathrm{M})$ or vehicle (DMSO) for 4 hours in culture. Nuclear protein was then incubated with a radiolabeled probe containing the consensus DNA binding sequence for PPAR $\gamma$ (Figure 4A). Figure 4 shows that Meg-01 cells have a constitutive level of active PPAR $\gamma$ (lane 2), which was increased by exposure to the natural PPAR $\gamma$ agonist $15 \mathrm{~d}_{-} \mathrm{PGJ}_{2}$ (lane 3 ) and to the synthetic PPAR $\gamma$ agonist ciglitazone (lane 4). A supershift using an anti-PPAR $\gamma$ antibody further supported PPAR $\gamma$ expression in Meg-01 cells (lane 6). We conclude that $15 \mathrm{~d}_{-} \mathrm{PGJ}_{2}$ and ciglitazone increase the activation of PPAR $\gamma$ in Meg-01 cells.

\section{Platelets have constitutively active PPAR $\gamma$ protein that has DNA binding ability}

EMSA was next performed to determine if platelet PPAR $\gamma$ protein can bind to the DNA PPAR response element. Lysates from 3 different rigorously purified platelet samples were incubated with a radioactive probe (PPAR $\gamma$ consensus DNA binding sequence) or cold probe (Figure 4B). A discrete DNA binding band appears in the 3 different platelet samples (lanes 2-4). The band disappears when extracts were incubated with excess cold probe (lanes 5-7). A supershift assay using a specific anti-PPAR $\gamma$ antibody was also performed and the bands shifted to a higher mass consistent with PPAR $\gamma$ (lanes 8-10). We also measured the ability of plateletderived PPAR $\gamma$ to bind its DNA consensus sequence using the TransAMTM PPAR $\gamma$ assay kit (Active Motif). In this method the 


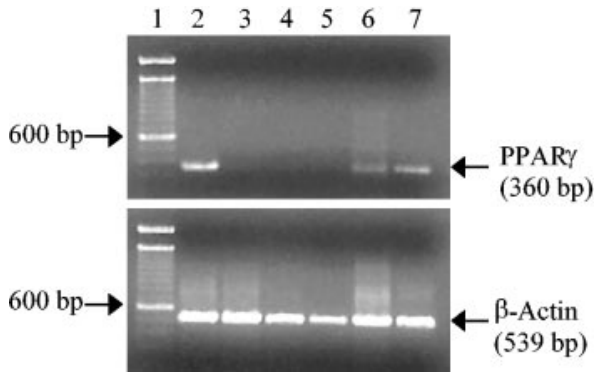

Figure 3. The human megakaryocyte cell line, Meg-01, but not human platelets express PPAR $\gamma$ mRNA. Total RNA was isolated from Meg-01 cells (lane 6) and human platelets (lanes 3-5) and reverse transcribed into cDNA. The cDNA was amplified with primers specific for $\beta$-actin (539-bp product, as a control) or PPAR (360-bp product). A 100-bp ladder was loaded in lane 1. Human adipose tissue (lane 2) and the human monocyte cell line (THP1; lane 7) were used as positive controls. Platelet samples were from a single donor (lane 3) or pooled from several donors (lanes 4-5). Reverse-transcriptase (-) controls were negative in all cases (data not shown).

consensus DNA sequence for PPAR $\gamma$ binding (or as a control, mutated oligonucleotides) is plate bound. A cell lysate is then added to the well, washed, and next incubated with an enzymeconjugated anti-PPAR $\gamma$ antibody that recognizes only DNA-bound PPAR $\gamma$. Following substrate addition, a colored product is formed. Platelets were exposed to buffer, $15 \mathrm{~d}_{-} \mathrm{PGJ}_{2}$, ciglitazone, or rosiglitazone $\left(20 \mu \mathrm{M}\right.$ for all) for 2 hours at $37^{\circ} \mathrm{C}$ and then protein was extracted. The measurements demonstrate that platelet PPAR $\gamma$ binds DNA even without treatment with PPAR $\gamma$ agonists, but binds 3- to 4-fold more strongly in the presence of PPAR $\gamma$ agonists (Figure 4C). The ability of platelet PPAR $\gamma$ to bind DNA in the absence of deliberate addition of PPAR $\gamma$ ligand suggests that platelets do contain an endogenous ligand. One possible ligand is lysophosphatidic acid, which platelets are known to produce. ${ }^{36}$ Overall, these results further support that platelets express PPAR $\gamma$ and that platelet PPAR $\gamma$ retains its DNA binding ability.

\section{PPAR $\gamma$ agonists prevent activated platelet release of CD40L, $\mathrm{TXB}_{2}$, and ATP and inhibit platelet aggregation}

We speculated that platelet PPAR $\gamma$ played a role in attenuating platelet activation. In order to begin to test the theory, we isolated human platelets and exposed them to the PPAR $\gamma$ ligands, $15 \mathrm{~d}_{-} \mathrm{PGJ}_{2}$ or rosiglitazone, for 15 minutes at $37^{\circ} \mathrm{C}$. Platelets were then incubated with buffer or with thrombin, a powerful platelet activator. Upon platelet activation, the cells expel key bioactive mediators important for thrombosis, inflammation, and vascular disease including CD40L and $\mathrm{TXB}_{2} \cdot{ }^{23,37}$ As shown in Figure 5, the release of $\mathrm{CD} 40 \mathrm{~L}$ and $\mathrm{TXB}_{2}$ was largely prevented in platelets exposed to a naturally occurring PPAR $\gamma$ agonist, $15 \mathrm{~d}-\mathrm{PGJ}_{2}$, as well as to rosiglitazone, a synthetic PPAR $\gamma$ agonist. The thrombininduced increase in platelet surface CD40L was also prevented by the PPAR $\gamma$ agonists as measured by flow cytometry (Figure 6).

To determine if a PPAR $\gamma$ agonist would inhibit platelet aggregation, the natural PPAR $\gamma$ agonist $15 \mathrm{~d}-\mathrm{PGJ}_{2}$ was added to PRP and aggregation and ATP release were stimulated with ADP. As shown in Figure 7, there was a concentration-dependent inhibition of platelet aggregation as shown by the results of a representative experiment. The initial slope of platelet aggregation, measured within the first 16 seconds after ADP addition, and the amplitude were significantly inhibited with $20 \mu \mathrm{M} 15 \mathrm{~d}-\mathrm{PGJ}_{2}$. The slope was $83 \pm 5 \%$ (mean $\pm \mathrm{SEM}$ ) of the normal (untreated) and the amplitude of aggregation was $64 \pm 11 \%$ of normal platelets (n $=7, P=.02$ for both). ATP release was also significantly inhibited by $20 \mu \mathrm{M} 15 \mathrm{~d}-\mathrm{PGJ}_{2}$ with a slope of $15 \pm 5 \%$ of normal and an amplitude of $22 \pm 10 \%$ of normal platelets $(\mathrm{n}=7, P<.0008$ for both). These findings support a role for PPAR $\gamma$ in downmodulating platelet activation.

\section{Discussion}

PPAR $\gamma$ is believed to be expressed only by nucleated cells since it is known as a transcription factor mainly located in the nucleus. ${ }^{38}$ However, recent studies have showed that PPAR $\gamma$ is not restricted to the nucleus, but is also expressed in the cytoplasm. ${ }^{2,3}$ Moreover, based on the emerging concept that platelets and their products enhance inflammation and atherogenesis, we hypothesized that human megakaryocytes and their cytoplasmic fragments, namely platelets, express PPAR $\gamma$.

Our results provide the first evidence that the Meg-01 cell line, human bone marrow megakaryocytes, and human platelets express PPAR $\gamma$. The presence of PPAR $\gamma$ protein was demonstrated by Western blotting with several different anti-PPAR $\gamma$ antibodies, immunocytochemistry, flow cytometry, and by peptide mapping analysis. As shown by EMSA and gel shift assay, the Meg-01 cell line and human platelets have active PPAR $\gamma$ protein with the ability to bind DNA. This was also shown by the TransAM PPAR $\gamma$ DNA binding assay. Megakaryocytes, the precursor cell of platelets, express a wide range of mRNA encoding for a variety of bioactive
A

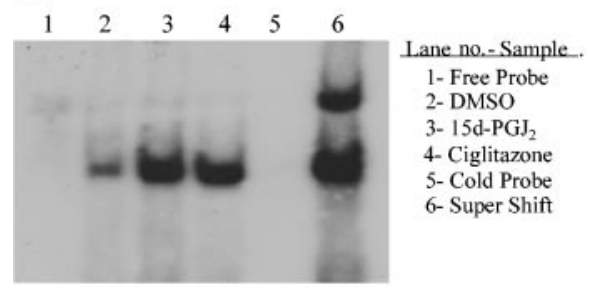

B

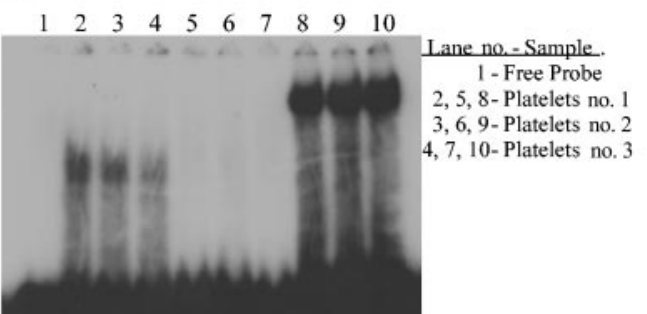

C

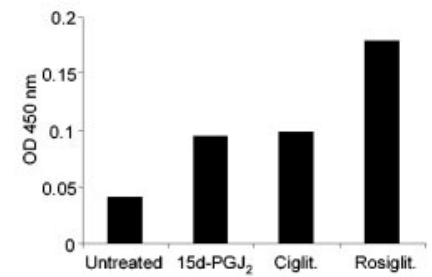

Figure 4. Meg-01 cells and human platelets contain PPAR $\gamma$ that binds the PPAR $\gamma$ DNA consensus sequence. (A) 15d-PGJ 2 and ciglitazone induce DNA binding of PPAR $\gamma$ protein in MEG-01 cells. After treatment with 15d-PGJ2 (lane 3) or ciglitazone (lane 4) or DMSO (vehicle control, lane 2), EMSA was performed. Lane 1 was loaded with free probe (no lysate), and lane 5 is nuclear extract from $15 d-P G J_{2}$-treated cells incubated with unlabeled probe (cold competitor) as a control for binding specificity. Lane 6 shows the locations of shifted and supershifted PPAR $\gamma$ (supershift with an anti-PPAR $\gamma$ antibody). Shift assays were repeated 3 times with similar results. (B) EMSA shows that platelets have PPAR $\gamma$ DNA binding activity. Platelet extracts were prepared without any treatment from 3 different pooled platelets as described in "Materials and methods." Lane 1 shows radioactive-labeled probe. Cell extracts $(50 \mu \mathrm{g})$ were incubated with ${ }^{32}$ P-labeled PPAR oligonucleotides (lanes 2-4) or cold competitor (unlabeled probe) (lanes 5-7) and run on a $4 \%$ nondenaturing gel. Lanes 8 to 10 indicate the locations of supershifted bands with anti-PPAR $\gamma$ antibody. (C) TransAMTM solid-phase PPAR $\gamma$ DNA binding activity measurements show that platelets have some active DNA binding PPAR $\gamma$ without treatment with PPAR $\gamma$ agonist. However, exposure to PPAR $\gamma$ agonist (20 $\mu \mathrm{M}$ $15 \mathrm{~d}-\mathrm{PGJ} \mathrm{J}_{2}$, ciglitazone, rosiglitazone) significantly enhances binding to the PPAR $\gamma$ DNA response element. Assay background in this experiment was 0.02 optical density (OD). 
A

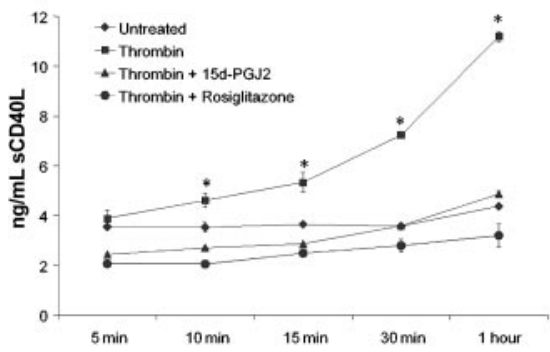

B

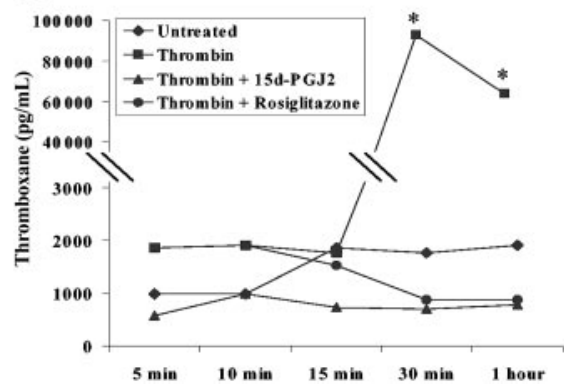

Figure 5. PPAR $\gamma$ agonists block platelet release of CD40L and $\mathrm{TXB}_{2}$. Purified human platelets were exposed to buffer or with $20 \mu \mathrm{M} 15 \mathrm{~d}-\mathrm{PG} \mathrm{J}_{2}$ or rosiglitazone for 15 minutes. The platelets were then activated with $0.8 \mathrm{U} / \mathrm{mL}$ thrombin and the supernatants collected at the times shown. Specific ELISA and enzyme immunoassays for CD40L (A) and $\mathrm{TXB}_{2}$ (B) levels were performed. (A) The increase in supernatant CD40L over time was statistically significant after thrombin activation compared with untreated or PPAR $\gamma$ agonist pretreated samples $(P=.0006$ by the log-rank test). There were no significant differences in CD40L release when comparing untreated samples with those treated with PPAR $\gamma$ agonist and thrombin. Mean \pm SD values are shown. (B) The increase in supernatant $\mathrm{TXB}_{2}$ over time was statistically significant after thrombin activation compared with untreated or PPAR $\gamma$ agonist and thrombin-treated platelets $(P=.0004$ by the log-rank test). These data are representative of 3 separate experiments. ${ }^{*}$ Significantly different from samples treated with $15 \mathrm{~d}-\mathrm{PGJ}_{2}$ or rosiglitazone.

mediators. ${ }^{39}$ The Meg-01 cell line was used to test for the presence of PPAR $\gamma$ mRNA, and these cells do express PPAR $\gamma$ mRNA. Interestingly, the enucleate platelet does express some mRNAs. ${ }^{33}$ However, while we found $\beta$-actin mRNA in platelets, no PPAR $\gamma$ mRNA was detected. This finding supports the concept that platelets have preformed PPAR $\gamma$ protein.

Our findings that platelets contain the transcription factor PPAR $\gamma$ and that PPAR $\gamma$ agonists blunt platelet activation suggest a novel nontranscriptional function for PPAR $\gamma$. The exact location of PPAR $\gamma$ in the platelet is unknown, but based on immunohistochemical staining of platelets (Figure 2B), it may be contained in granules with the bulk of the PPAR $\gamma$ being distributed throughout the platelet. Since there is abundant PPAR $\gamma$ permeating the platelet, it will likely have a pivotal role in regulating multiple platelet functions. Clearly, platelet PPAR $\gamma$ retains its DNA binding ability, which would appear to be unneeded in platelets; we therefore suggest that PPAR $\gamma$ must also possess other functions, which may include interactions with intracellular platelet proteins. There are several steps during platelet exocytosis wherein PPAR $\gamma$ could interfere, including calcium or protein kinase $\mathrm{C}$ signaling pathways, rearrangement of the cytoskeleton during platelet activation, or docking and fusion of granules with the plasma membrane. Further studies to determine the novel PPAR $\gamma$ targets in platelets will be necessary to thoroughly define the mechanism of platelet inhibition by PPAR $\gamma$ agonists.

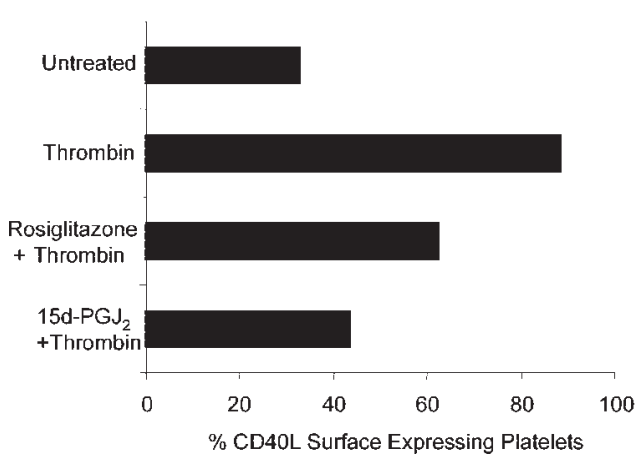

Figure 6. PPAR $\gamma$ agonists block the thrombin-induced increase in platelet surface CD40L expression. Purified human platelets were exposed to $20 \mu \mathrm{M}$ $15 \mathrm{~d}-\mathrm{PG} \mathrm{J}_{2}$ or rosiglitazone for 15 minutes and were then stimulated with $0.8 \mathrm{U} / \mathrm{mL}$ thrombin for 60 minutes. The platelets were then stained and prepared for flow cytometry with a monoclonal antihuman CD40L antibody or with control isotype antibody. The graph shows a representative experiment with the results presented as the percent of surface $C D 40 \mathrm{~L}^{+}$platelets.
Little is known about the in vivo ligands for PPAR $\gamma$. One possibility in the bone marrow is that megakaryocytes generate $15 \mathrm{~d}-\mathrm{PGJ}_{2}$, as they are known to produce its precursor $\mathrm{PGD}_{2} \cdot{ }^{40}$ This could modulate PPAR $\gamma$ activity in the bone marrow. PPAR $\gamma$ may be involved in the differentiation and proliferation of bone marrow cells and may have additional immunologically relevant effects in erythroid, myeloid, monocytic, megakaryocytic, T- and Blymphocytic, stromal, and endothelial cell function. In the study described herein, we demonstrate that $15 \mathrm{~d}-\mathrm{PGJ}_{2}$ and the thiazolidinedione class of antidiabetic drugs, ciglitazone and rosiglitazone, play an important role in attenuating platelet activation. This was demonstrated by the ability of PPAR $\gamma$ agonists to block thrombin-induced platelet release of $\mathrm{TXB}_{2}, \mathrm{CD} 40 \mathrm{~L}$, and surfaceassociated CD40L. In addition, the PPAR $\gamma$ agonist $15 \mathrm{~d}_{-} \mathrm{PGJ}_{2}$ blunted ADP-induced platelet aggregation and ATP release. Platelets, the most numerous, enucleate, and tiny blood cells, are not only essential for clotting, but are broadly involved in inflammation and pathogenesis. Platelets contain proinflammatory and bioactive mediators that include transforming growth factor- $\beta$, prostaglandins, thromboxanes, and CD40L. TXA 2 potentiates platelet aggregation at concentrations produced by activated platelets and mediates fever and inflammation by induction of the Cox-2

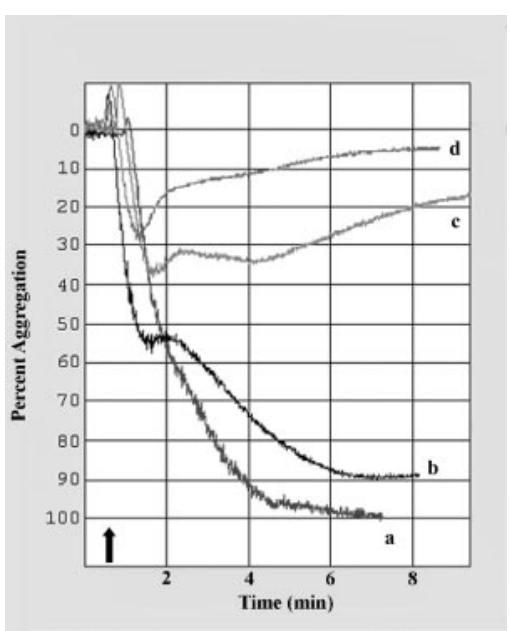

Figure 7. The PPAR $\gamma$ agonist $15 \mathrm{~d}-\mathrm{PGJ}_{2}$ inhibits platelet aggregation induced by ADP. Platelet aggregation was stimulated by addition of $5 \mu \mathrm{M}$ ADP in the absence (a) or presence of $5 \mu \mathrm{M}$ (b), $10 \mu \mathrm{M}$ (c), or $20 \mu \mathrm{M}$ (d) $15 \mathrm{~d}-\mathrm{PGJ}_{2}$. Addition of ADP is indicated by the arrow. $15 \mathrm{~d}-\mathrm{PGJ}_{2}$ dose dependently inhibited platelet aggregation. Shown is 1 representative experiment of 7 . 
enzyme. ${ }^{41,42}$ Platelets have the highest expression of CD40L of any human cell. Platelet-released CD40L, as well as CD40L expressed on the platelet surface, could activate nearby CD40-expressing cells. Recent studies show that platelets contribute to mucosal inflammation and the atherosclerosis process by expressing and releasing CD40L. ${ }^{24,28} \mathrm{CD} 40 \mathrm{~L}$ is now also considered a primary platelet agonist. ${ }^{43}$ Since platelets are activated by their own released $\mathrm{CD} 40 \mathrm{~L}$ through $\mathrm{B}_{3}$ integrin binding, a decrease in $\mathrm{CD} 40 \mathrm{~L}$ by PPAR $\gamma$ ligands could reduce platelet activation, including thrombosis. ${ }^{43}$ Patients with unstable angina have higher blood concentrations of CD40L than healthy people, perhaps due to release from activated platelets. ${ }^{44}$ Platelet surface expression of CD40L and evidence for high CD40L levels in atheromatous plaques have served to focus attention on platelets in atherosclerosis. CD40-CD40L interaction promotes proinflammatory and proatherogenic effects in vitro and in vivo. ${ }^{45}$ It has been shown that the binding of CD40L to its corresponding cellular receptors stimulates production of other proinflammatory cytokines, such as tumor necrosis factor-alpha and IL-1 by leukocytes and vascular endothelium. ${ }^{22}$

The pathogenesis of type 1 and type 2 diabetes involves inflammation with elevated blood levels of CD40L as in atherosclerosis. ${ }^{46}$ PPAR $\gamma$-activating thiazolidinediones, novel insulinsensitizing antidiabetic agents, have been shown to exhibit antiinflammatory effects. ${ }^{6,12}$ Interestingly, it was recently shown that treatment of diabetic patients with a thiazolidinedione-type drug decreased circulating CD40L blood levels. ${ }^{46,47}$ Based on our findings, we speculate that the reduced blood levels of CD40L in that study could have been due to inhibition of platelet release of CD40L by the dampening effects of the PPAR $\gamma$ agonist drug. Furthermore, our findings that the PPAR $\gamma$ agonist $15 \mathrm{~d}-\mathrm{PGJ}_{2}$ inhibited platelet aggregation and ATP release support a potential therapeutic approach to inhibit platelet function in diabetics and other patients. Obviously, further clinical study is required to fully evaluate the effects of natural and synthetic PPAR $\gamma$ agonists on platelets in human beings.

The foundation studies we report demonstrating platelet PPAR $\gamma$ expression and its role in tempering platelet activation have revealed a novel target for PPAR $\gamma$ agonists. The emerging role of platelets as mediators of inflammation suggests that some of the anti-inflammatory effects of PPAR $\gamma$ may be mediated through dampening platelet activation, especially CD40L release. Our findings support continued evaluation of natural and synthetic PPAR $\gamma$ agonists as regulators of thrombosis and anti-inflammatory agents.

\section{Acknowledgments}

We thank Rosemary Ziemba-Ball for providing human bone marrow smears, and Chantal Turner and Kathryn Seweryniak for performing some of the ELISAs. We also thank Brian H. Smith and Stephen Pollock for providing technical assistance.

\section{References}

1. Daynes RA, Jones DC. Emerging roles of PPARs in inflammation and immunity. Nature Rev Immunol. 2002;2:748-759.

2. Padilla J, Leung E, Phipps RP. Human B lymphocytes and B lymphomas express PPAR- $\gamma$ and are killed by PPAR- $\gamma$ agonists. Clin Immunol. 2002; 103:22-33.

3. Kelly D, Campbell JI, King TP, et al. Commensal anaerobic gut bacteria attenuate inflammation by regulating nuclear-cytoplasmic shuttling of PPAR- $\gamma$ and Rel A. Nat Immunol. 2004:5:104112.

4. Spiegelman BH, Hu E, Kim JB, Brun R. PPAR gamma and the control of adipogenesis. Biochemie. 1997;79:111-112.

5. Fajas L, Auboeuf D, Raspe E, et al. The organization, promoter analysis and expression of the human PPAR $y$ gene. J Biol Chem. 1997;272:1877918789.

6. Ricote M, Li AC, Willson TM, Kelly CJ, Glass CK The peroxisome proliferator-activated receptorgamma is a negative regulator of macrophage activation. Nature. 1998;391:79-82.

7. Harris SG, Phipps RP. Prostaglandin $D_{2}$, its metabolite 15-d-PGJ , and peroxisome proliferator activated receptor-gamma agonists induce apoptosis in transformed, but not normal, human T lineage cells. Immunology. 2002;105:23-34.

8. Su CG, Wen X, Bailey ST, et al. A novel therapy for colitis utilizing PPAR-gamma ligands to inhibit the epithelial inflammatory response. J Clin Invest. 1999;104:383-389.

9. Marx N, Bourcier T, Sukhova GK, Libby P, Plutzky J. PPAR gamma activation in human endothelial cells increases plasminogen activator inhibitor type-1 expression: PPAR gamma as a potential mediator in vascular disease. Arterioscl Thromb Vascular Biol. 1999;19:546-551.

10. lijima K, Yoshizumi M, Ako J, et al. Expression of peroxisome proliferator-activated receptor gamma (PPAR gamma) in rat aortic smooth muscle cells. Bioch Biophys Res Comm. 1998; 247:353-356.
11. Lee $\mathrm{Y}$, Huang TS, Yang ML, Huang LR, Chen $\mathrm{CH}$, Lu FJ. Peroxisome proliferation, adipocyte determination and differentiation of $\mathrm{C} 3 \mathrm{H} 10 \mathrm{~T} 1 / 2$ fibroblast cells induced by humic acid: induction of PPAR in diverse cells. J Cell Physiol. 1999;179: 218-225.

12. Jiang C, Ting AT, Seed B. PPAR-gamma agonists inhibit production of monocyte inflammatory cytokines. Nature. 1998;391:82-86.

13. Padilla J, Kaur K, Cao HJ, Smith TJ, Phipps RP Peroxisome proliferator activator receptor- $\gamma$ agonists and 15-Deoxy- $\Delta^{12,14}-\mathrm{PGJ}_{2}$ induce apoptosis in normal and malignant B-lineage cells. J Immunol. 2000;165:6941-6948.

14. Jackson L, Wahli W, Michalik L, et al. Potentia role for peroxisome proliferator activated receptor (PPAR) in preventing colon cancer. Gut. 2003;52: 1317-1322.

15. Mueller E, Sarraf $P$, Tontonoz $P$, et al. Terminal differentiation of human breast cancer through PPAR gamma. Mol Cell. 1998;1:465-470.

16. Teramura M, Kobayashi S, Hoshino S, Oshi K, Mizoguchi H. Interleukin-11 enhances human megakaryocytopoiesis in vitro. Blood. 1992;79: 327-331.

17. Burstein SA, Downs T, Friese P, et al. Thrombocytopoiesis in normal and sublethally irradiated dogs: response to human interleukin-6. Blood. 1992;80:420-428.

18. Bentfeld-Barker ME, Bainton DF. Identification of primary lysosomes in human megakaryocytes and platelets. Blood. 1982;59:472-481.

19. Scheuerer B, Ernst M, Dürrbaum-Landmann I, et al. The CXC-chemokine platelet factor 4 promotes monocyte survival and induces monocyte differentiation into macrophages. Blood. 2000;95: 1158-1166.

20. Gear AR, Camerini D. Platelet chemokines and chemokine receptors: linking hemostasis, inflammation, and host defense. Microcirculation. 2003; 10:335-350.

21. Vezza R, Roberti R, Nenci GG, Gresele P. Pros- taglandin E2 potentiates platelet aggregation by priming protein kinase C. Blood. 1993;82:27042713.

22. Phipps RP. Atherosclerosis: The emerging role of inflammation and the CD40-CD40 ligand system. Proc Natl Acad Sci U S A. 2000;97:6930-6932.

23. Phipps RP, Kaufmann J, Blumberg N. Platelet derived CD154 (CD40 ligand) and febrile responses to transfusion. Lancet. 2001;357:20232024.

24. Danese $S$, de la Motte $C$, Sturm A et al. Platelets trigger a CD40-dependent inflammatory response in the microvasculature of inflammatory bowel disease patients. Gastroenterology. 2003;124: 1249-1264.

25. Henn V, Slupsky JR, Gräfe M, et al. CD40 ligand on activated platelets triggers an inflammatory reaction of endothelial cells. Nature. 1998;391: 591-594.

26. Mach F, Schonbeck U, Libby P. CD40 signaling in vascular cells: a key role in atherosclerosis? Atherosclerosis. 1998;137:S89-S95.

27. Linton MF, Fazio S. Cyclooxygenase-2 and atherosclerosis. Curr Opin Lipidol. 2002;13:497-504.

28. Heeschen C, Dimmeler S, Hamm CW, et al. Soluble CD40L in acute coronary syndromes. New Engl J Medicine. 2003;348:1104-1111.

29. Schonbeck U, Varo N, Libby P, Buring J, Ridker $\mathrm{PM}$. Soluble CD40L and cardiovascular risk in women. Circulation. 2001;104:2266-2268.

30. Ogura M, Morishima Y, Ohno R, et al. Establishment of a novel human megakaryoblastic leukemia cell line, MEG-01, with positive Philadelphia chromosome. Blood. 1985;66:1384-1392.

31. Andrews NC, Faller DV. A rapid micropreparation technique for extraction of DNA binding proteins from limiting numbers of mammalian cells. Nucleic Acids Res. 1991;19:2499.

32. Born GVR. Quantitative investigations into the aggregation of blood platelets. J Physiol Lond. 1962;162:67-68. 
33. Gnatenko DV, Dunn JJ, McCorkle SR, Weissmann D, Perrotta PL, Bahou WF. Transcript profiling of human platelets using microarray and serial analysis of gene expression. Blood. 2003;101: 2285-2293.

34. Inwald DP, McDowall A, Peters MJ, Callard RE, Klein NJ. CD40 is constitutively expressed on platelets and provides a novel mechanism for platelet activation. Circ Res. 2003;92:1041-1048.

35. Juge-Aubry C, Pernin A, Favez T, et al. DNA binding properties of peroxisome proliferator-activated receptor subtypes on various natural peroxisome proliferator response elements. J Biol Chem. 1997;272:25252-25259.

36. Mclntyre TM, Pontsler AV, Silva AR, et al. Identification of an intracellular receptor for lysophosphatidic acid (LPA): LPA is a transcellular PPAR gamma agonist. Proc Natl Acad Sci U S A. 2003 100:131-136.

37. Best LC, Holland TK, Jones PB, Russell RG. The interrelationship between thromboxane biosynthesis, aggregation and 5-hydroxytryptamine secretion in human platelets in vitro. Thromb Haemost. 1980;43:38-40.
38. Murphy G, Holder J. PPAR $\gamma$ agonists: therapeutic role in diabetes, inflammation and cancer. Trends Pharmacol Sci. 2000;21:469-474.

39. Soslau G, Morgan DA, Jaffe JS, Brodsky I, Wang Y. Cytokine mRNA expression in human platelets and a megakaryocytic cell line and cytokine modulation of platelet function. Cytokine. 1997;9: 405-411.

40. Greene MJ, Pitts J, McCarville MA, et al. PPAR gamma: Observations in the hematopoietic system. Prostaglandins Other Lipid Mediat. 2000;62: 45-73.

41. Halushka PV, Rogers RC, Loadholt CB, Colwell JA. Increased platelet thromboxane synthesis in diabetes mellitus. J Lab Clin Med. 1981;97:87-96.

42. Caughey GE, Cleland LG, Gamble JR, James MJ. Up-regulation of endothelial cyclooxygenase- 2 and prostanoid synthesis by platelets. Role of thromboxane A2. J Biol Chem. 2001;276: 37839-37845.

43. Prasad KS, Andre P, He M, Bao M, Manganello J, Phillips DR. Soluble CD40 ligand induces $\beta_{3}$ integrin tyrosine phosphorylation and triggers platelet activation by outside-in signaling. Proc Natl Acad Sci U S A. 2003;100:12367-12371.

44. Aukrust $P$, Muller F, Ueland T, et al. Enhanced levels of soluble and membrane-bound CD40 ligand in patients with unstable angina. Possible reflection of $\mathrm{T}$ lymphocyte and platelet involvement in the pathogenesis of acute coronary syndromes. Circulation. 1999;100:614620.

45. Lutgens E, Cleutjens KBJM, Heeneman S, Koteliansky VE, Burkly LC, Daemen MJAP. Both early and delayed anti-CD40L antibody treatment induces a stable plaque phenotype. Proc Natl Acad Sci U S A. 2000;97:7464-7469.

46. Varo N, Vicent D, Libby $P$, et al. Elevated plasma levels of the atherogenic mediator soluble CD40 ligand in diabetic patients: a novel target of thiazolidinediones. Circulation. 2003;107:2664-2669.

47. Marx N, Imhof A, Froehlich J, et al. Effect of ro siglitazone treatment on soluble CD40L in patients with type 2 diabetes and coronary artery disease. Circulation. 2003;107:1954-1957. 